\title{
The Hungarian Pensions Guarantee Fund
}

Received 9th March, 2000

\section{John Kenworthy}

is Managing Director of Atkus Consulting Ltd. His last official appointment was at Under-Secretary level as Chief Executive of the Information Technology Services Agency of the Department of Social Security. He has been operating as an independent consultant in various capacities since 1993.

\begin{abstract}
During 1997, and following World Bank advice, the Republic of Hungary introduced 'second pillar' compulsory private pensions for new entrants to the Hungarian labour market from June, 1998; voluntary entry was available before that date. The European Commission offered advice under the PHARE Programme, and in respect of Hungary's status as an applicant country to the European Union. This paper reviews the practical matters involved in providing guarantee to contributors subscribing to Private pension Funds in Hungary; the actuarial issues encountered in generating sufficient financial reserves to provide for such guarantees; and the likely impact of EU directives of Hungarian national pension guarantee legislation. The advice was tendered to the Ministry of Finance and the Pensions Guarantee Fund (Penztarak Garancia Alapja) and validated by the European Commission.
\end{abstract}

Keywords: Europe; Hungary; private pensions; identifier data; actuarial; guarantees; directive

\section{Introduction}

At the end of 1998, Aktus Consulting Ltd. was contracted by the European Commission through the medium of the PHARE Consensus II Programme to provide advice to the Hungarian Pensions Guarantee Fund (PGF). The PHARE Programme is concerned with (among other issues) advising applicant states on issues concerning eventual accession to the European Union. The PGF was set up in 1998 by Hungarian

Tel: 0208208 1043; Fax: 02084526295 ;

e-mail:

aktusconsulting@aol.com www.aktusconsulting.co.uk)
Parliamentary legislation (passed in 1997) to provide guarantees to individual savers in Hungary who are obliged, by law, to open 'Second Pillar' pensions accounts. These accounts are held by private pensions providers with the purpose of establishing future pension entitlements over and above those provided by the state national insurance scheme (the 'First Pillar'). The regulations and calculations are, to say the least, complex and will not be rehearsed in this short paper. It is important to understand, also, that as some of the information may be market sensitive, it must remain confidential to the client. The intention here is simply to illustrate some of the key issues faced during the project and attempt to draw some conclusions of general application from them.

It should noted that the project was resource limited $a b$ initio, and that our original Terms of Reference (TOR) required us to advise on the construction of new Laws \& Regulations for the establishment of a compulsory pensions 
guarantee system in Hungary. In fact, we found ourselves instead having to conduct a review of legislation already passed and in operation. This necessitated an early reassessment of our priorities within the project. Also, as is so often the case in these exercises, the TOR were effectively infinite in scope and the resources finite in provision. We dealt with them by producing a set of provisional recommendations with the intention of focusing the directions of our work, with the agreement of the client, to ensure that practical measures could be generated at the close of the contract.

In the event, the issues with which we dealt fell in to three categories. The first focused on the financial viability and actuarial dynamics of the Pensions Guarantee Fund in the medium and long term. The second comprised the day-to-day activities of the Fund, under legislation as it then stood - or could be modified, and data acquisition and information management systems of the Fund. This also covered relationships with other authorities such as the Ministry of Finance and State Private Funds Supervision (SPFS) and the Private Pension Funds (PPFs) themselves. The third covered questions of the impact of European Union instruments and accession requirements. The latter had to take cognisance, too, of the implications which extant Hungarian compulsory second-pillar pensions legislation has for the rights of migrant workers in Hungary today. There was, of course, a whole series of subsidiary issues falling within these broad categories.

\section{A matter of principle}

At the very outset, however, we were asked (somewhat surprisingly) for a view whether there should be a (compulsory) private pensions guarantee fund at all, notwithstanding that the new system had only just been put into place.

Furthermore, some $2 \mathrm{~m}$ Hungarians, out of a workforce of approximately $4 \mathrm{~m}$ (from a population of $10 \mathrm{~m}$ ), were already members of a private pension scheme by the end of 1999. It should be remarked here that, from passing of the legislation in $1997^{1}$ till 1st June, 1998, everyone (effectively under the age of 42 at that time) already in employment was encouraged to join a private pension scheme voluntarily. From 1st June, 1998, all new entrants to the Hungarian labour market were required by law to become members of, and contribute to, a private pension scheme. As we began our work in the winter of 1998/99, new PPF members were enrolling at a rate of some 100,000 per month. In the light of this, to advise termination of a newly established (and publicised) guarantee scheme would have been both unfair and politically unsound.

Furthermore, there is here, in our view, a question of general principle. For an individual to be required by law to put a proportion of their personal earnings or financial assets in the hands of a third party puts a responsibility upon the State to ensure some form of guarantee that those monies be not lost nor squandered, but invested wisely on behalf of the individual contributor. At least, in national pension insurance schemes, the State usually guarantees a level of pension for those citizens meeting the eligibility criteria. (Whether the sums actually paid are adequate or satisfactory is another issue.) In the case of a compulsory second-pillar pensions scheme, we felt that some comparable undertaking should be made by the state imposing this requirement on its citizens, and that this provided a legitimate and defensible principle on which to base our subsequent analysis. Whether the establishment of yet another fund is the 
most advisable or practicable way of achieving this guarantee is a separate issue. We were quite sensitive to the concerns of double jeopardy, which form the basis of most objections to the establishment of separate guarantee funds. Thus, unscrupulous fund managers would be tempted to take unreasonable risks with their clients' money, in the safe knowledge that, in the case of fund failure, the taxpayer would pick up the tab.

\section{The Pensions Guarantee Fund}

The Pensions Guarantee Fund in Hungary is a small organisation, comprising a permanent staff of six, supervised by a Board of around 12 drawn from interested parties such as the Ministry of Finance, the State Private Funds Supervision and the National Deposit Insurance Fund. Since our Report, a representative of the National Bank of Hungary has also been invited to join the Board. It was established by law as an independent legal entity and is financed by a levy (of currently 0.4 per cent of PPF members' contributions) made on the operating PPFs registered with the SPFS. A small part of the levy pays for the upkeep of the PGF itself; the larger proportion being invested by the Fund for use on the occasions when statutory guarantee provisions come in to play. At the beginning of our investigation, we noted that the law required the PGF to take responsibility for the management of the pension portfolio of any individual pension fund member (or group of the same), for a period of up to six months on simple request. We pointed out that this was costly and administratively impractical as well as totally unnecessary. The Guarantee Fund should operate as the financial back-stop when the supervisory mechanism had failed to prevent a financial problem with a fund, or the inadequacies in the management of one. Implementation of this part of its remit would put the Guarantee Fund in the anomalous position of guaranteeing itself, and becoming a de facto Private Pension Fund subject to the SPFS. These provisions have now been removed. At present, the main statutory functions of the PGF, briefly stated, are that:

- on retirement, each retiree is

guaranteed a minimum benefit at least equivalent to the normative pension, ie, 25 per cent of the state pension to which the person would be entitled;

- on transfer (or death) of a PPF member, the PGF guarantees that if the PPF is unable to transfer the full account balance to the new fund (beneficiaries), then the PGF will the make up the difference;

- on transfer, a member who is currently receiving a pension is guaranteed a transfer value at least equivalent to the 'member's claim';

- if a pension fund's reserves are insufficient to meet pensions currently being paid (and including increases to those payments) then the PGF will supplement the reserves.

Apart from meeting certain costs, levies received by the PGF are invested with the primary purpose of either replacing the assets of a defaulting fund, or ensuring, at least, that pensions in payment are maintained while another private fund can be found to adopt these fund members. The remaining assets of a fund under liquidation could be transferred to the new fund. Beyond this, and even if a PPF does not actually default upon pensions (or annuity payments,) the PGF is required to guarantee the 'normative' pension, defined as 25 per cent of the state pension ${ }^{2}$ to which the pensioner would be entitled at 
the particular point in time. In practice, this would be a pretty small sum; nonetheless, it is open to question how long the Guarantee Fund could maintain such a position. On the one hand, there are restrictions placed upon the investment opportunities of private pension funds (almost entirely in Government bonds at present). On the other hand, the government of the day has the freedom to raise or alter the basic state pensions at will, and at any time in the future, without consideration of the consequent effects upon the second-pillar pensions guarantee system.

The Government rightly wants to ensure that those who will in future obtain a private-funded pension in place of a non-funded state pension will not lose out as a result. The normative pension is currently set at a level, which in reasonably foreseeable circumstances private pension schemes could be expected to be able to provide. However, capital markets fluctuate, as do investment returns. Effectively therefore, the current obligation placed on the PGF to guarantee the normative pension means that the PGF must be prepared to counter the effect of any major fall in the markets over which it has no control.

Possibly more seriously but less likely, could be the activation of the obligation of the Guarantee Fund to replace the lost assets of a failed PPF. On the assumption that supervisory systems work effectively, this should either simply not happen or, at least, occur with sufficient warning to take preparative action. It is hard to see how any guarantee fund could generate such wealth of assets to meet such an open-ended commitment. What is more likely in practice is that the Fund might have to finance the maintenance of pensions currently in payment whilst alternative arrangements are found within the industry. In fact, the bulk of private pensions arrangement now being established in Hungary are administered by the top half dozen or so large insuring institutions operating in Hungary, and a longish tail of smaller funds. There is no reason to expect that any of the large funds will default on their asset management obligations and, as far as the smaller fry are concerned, a measured and sensible process of consolidation is in process. Nevertheless, with the high-profile Maxwell debacle still clear in our minds, we did advise that at least some modest contingency planning would be sensible, and that closer, regular working with the SPFS than has yet been established should be instigated.

Without going into further actuarial and financial detail here, our advice on the viability of the Pensions Guarantee Fund on these issues was to look very carefully at the nature of the long-term potential liabilities of the guarantee fund vis-à-vis the individual pensions guarantees. The Fund and its advisors should continue to examine, on an iterative basis, how such obligations should be modified or realistically undertaken over time. A single study such as ours could only produce one set of predictions based on a small number of data-sets, which could do little more than generate projections which illuminate a problem which should be addressed. More importantly, it was an objective to establish an agreed methodology, which was done. On this basis, further refinement in the light on fresh data and under varying assumptions will always be needed to check the sensitivity of the analysis, as a continuing component of usual management activity in these circumstances.

At this point it is important to record that the 'second pillar' compulsory pensions system in Hungary is very new - hardly much more than two and a 
half years' old at the time of writing. The introduction of the scheme into Hungary has been a notable success, especially during the voluntary period and is to be admired. The increase in the rate of saving by Hungarian citizens, particularly at a time of high inflation, has to be respected. This bodes well from the macro-economic point of view, provided that restrictions on the options for investment by the PPFs are further relaxed in accordance with EU Directives in the financial services field, so that entrepreneurial sectors of the economy can gain access to greater liquidity. Both the Hungarian authorities and the fund providers themselves were surprised by the levels of response and it is to their credit that, after the initial shock, the proper allocation of contributors to their accounts was successfully completed during the 1999 financial year.

More generally, such a system has not been attempted elsewhere in quite the same way, so it was to be expected that a learning period would be experienced by those concerned. This contrasts with the very long experience in the United Kingdom in the field of occupational pensions, funded and managed by both state and non-state organisations and business and covering a large proportion of the employed population and supported by a huge and sophisticated money market.

However, there are always complications, and one of the issues to be addressed in Hungary has been the effect on the national state pensions system. The 'second pillar' arrangement has obviously resulted in a drop in revenue for the National Pensions Insurance Administration (NPIA.) Instead of receiving some 6 per cent of salary from each employee, the NPIA is now receiving only 1 per cent from the increasing numbers now falling within the compulsory private pensions scheme. ${ }^{3}$ The balance, of course, now flows in to the coffers of the PPFs. Yet the 'second pillar' scheme is only just accumulating assets at the beginning of a long-term investment programme in order to pay pensions or fund annuities many years from now. The NPIA, on the other hand, is obliged to fund the payment of current pensions out of a stock of financial resources no longer being replenished at the previous rate. In short, the Pay-As-You-Go aspect of Hungary's national insurance pension scheme needs topping up from Central Government, and there is some debate in Hungary whether the fiscal forecasts originally made to deal with this expected problem were adequate. Indeed there have been, in the past, considerable difficulties in collecting health and pensions insurance contributions in Hungary.

\section{The PGF and sister organisations in the Hungarian pensions system}

As indicated above, the Pensions

Guarantee Fund is an organisation which, though statutorily independent, is intimately associated with other state and non-state organs with close interests on the economic and financial aspects of social protection provision in Hungary, whether public or private. It is currently a rather mocked business cliché to say that issues should be examined holistically but, in the case of our study of the role and capabilities of the PGF, its interactions (and exchanges of information) with other bodies required our attention. In particular, the PGF must work closely with State Private Funds Supervision, which is the principal supervisory body covering the private pension fund sector in Hungary. The SPFS is effectively a creature of the Ministry of Finance. Its senior officers are 
appointed by the Minister and its President reports to him. If a public or private entity, or even a number of individuals grouping together - there has to be a minimum of 2,000 members - decide to set up a fund, they must register with the Supervision. The SPFS is empowered to examine the books of the fund to ensure good behaviour and financial management and require that remedial action is taken if necessary. Regular and detailed reporting to the SPFS is a feature of the PPFs' statutory obligations, and the detail and nature of the financial and administrative information to be returned is laid down by law.

The Supervision is a much larger organisation than the PGF, possessing some 70 staff and an extensive IT system. It receives a stream of information from the PPFs and publishes regular bulletins on the activities of the funds registered. In particular, the Supervision is charged with maintaining up-to-date records and information concerning the status of the PPFs and their members, while the PGF should, inter alia, itself analyse the investment performance of the funds 'in connection with the required rate of return ... to cover pensions services. ${ }^{4}$ The various Laws and Decrees are quite clear that the Supervision is obliged to provide regular information to the PGF and that information exchange systems should be established to achieve this. We were a little surprised that more progress had not been made in this area before our study was set in hand, and we urged that it should be undertaken without delay. It is not a matter of great technical difficulty.

Looking even more widely than the PGF and SPFS for a moment, all our work in Hungary in the social protection field has led us constantly to raise concerns about the quality of basic information and individual identification data in Hungary. The genesis of this difficulty lies in the fissiparation and employment structures in Hungary due to the demise of large state-owned structures since 1990. Where there was a relative small number of employer organisations administering a range of social protection services, Hungary now boasts some 300,000 'enterprises'; the average number of employees has fallen dramatically, and labour mobility has made it much more difficult for state organisations to maintain records - and collect social protection contributions.

Our previous report for the Hungarian Ministry of Finance ${ }^{5}$ dealt at length with the issue of poor quality of base data, and the need for extensive remedial action over the whole field. One of our principal recommendations - that the state taxation authority ${ }^{6}$ should take over responsibility for social insurance collections - is only just now being implemented. It is from this source that the National Pensions Insurance Administration receives the flow of income to maintain its own set of national individual insurance accounts, regardless of whether a citizen has, or has not, opened a second pillar savings scheme. In the case of problems with a particular Private Pension Fund, individual account information held by the NPIA on the one hand and the Fund on the other must match. The relevance of this to the work of the PGF is that the PGF is reliant, at the end of the day, in the efficient working of a whole web of data and information flows which must accurately reflect the most recent state of the accounts of many thousands of individual pensions savings account holders. If an emergency were to occur then the PGF and the Supervision would need fast access to the most up-to-date and accurate information very quickly, so that speedy action can be taken to protect individual depositors.

The need to focus on the individual 
citizen and not operate in the previous 'top-down' organisational philosophy, while recognising that citizens have rights and identities separate from those of the state, has presented a serious challenge to all social protection organisations, who are now required to maintain accurate records of shifting and increasingly mobile working population. The demands on record systems to be continually updated and effectively crossreferenced are severe. The National Pensions Insurance Administration is spending considerable effort on scanning into its computer system approximately $80 \mathrm{~m}$ paper-based records. Yet up-to-date lists of contributors will still only be available annually, and will not yet be readily referenced to individual account holders in the PPFs. This implies that when issues of normative pension guarantee begin to emerge in the future, decision taking on individual cases will be a long and painstaking business. It is ironic that Hungary's vigorous and overcumbersome post-1990 data protection laws are, in many respects, having the opposite effect to that intended. Thus, making a speedy and accurate connection between the citizen and his savings is being impeded rather than enhanced.

The National Bank of Hungary $(\mathrm{NBH})$ and the Ministry of Finance both have a close interest in the activities of the PGF. The presence of these institutions on the Board of the PGF represents a close and legitimate interest in the issues we raised in our analysis, touching on the capability of the Guarantee Fund to meet its statutory responsibilities, especially in crisis. This has been a view expressed in Hungary that the Guarantee Fund can only ever be a stepping stone to the national budget in case of an inability of a PPF or PPFs and the Guarantee Fund to meet their obligations. Indeed, the establishing legislation specifically recognises the role of the national budget as final guarantor. ${ }^{7}$ In light of this, the PGF should be seen only as part of a private pension fund guarantee system, an outward expression of a determination that the pension rights of members of mandatory pension funds and their individual assets should be protected. Nonetheless, the Guarantee Fund does possess a reservoir of monies which can be used as 'cash at short call' in such circumstances. Furthermore, the Board of Directors of the PGF are also empowered to raise a further levy on the industry as a whole to increase cash availability, if need be. ${ }^{8}$ A parallel here with the ability of the Pensions Compensation Board in the UK to raise a further levy on the pensions industry in Britain is illuminating. In sum, it may be said that a second-pillar pensions guarantee system is coming into place in Hungary, though in our view we believe that supporting administrative systems leave something to be desired and that the magnitude and nature of the guarantees actually offered to the citizen need further review and examination at national level.

There is circularity in that the more successful private pensions schemes become in a country, and the greater the asset base under pensions fund management, it will become less easy for the national government to guarantee those assets independently — it becomes arithmetically impossible. Thus the weight of responsibility must fall on the quality of supervision on the one hand, and a determination of the industry to (publicly) keep its own house in order on the other.

\section{Accession to the European Union and the acquis communitaire}

Our work in Hungary was financed by the European Union's PHARE programme set up to advise certain East 
European countries. Undoubtedly, this provided us with one of our more difficult tasks, caused mainly by high levels on uncertainty during the life of the project as a result of the widespread changes in Brussels consequent upon the resignation of the Santer Commission.

Additionally, we had to counter an initial belief among some members of the Hungarian administration that there existed within the EU a written, universal code of practice which could be compared easily and contrasted with current Hungarian legislation and, quite separately, deal with another opinion that, at this stage at any rate, EU directives did not impinge at all upon Hungarian pensions arrangements. In covering this part of the project, various Hungarian delegations visited the relevant institutions in the UK (including professional asset managers in the City) and heard presentations given by authorities from other Members States.

As far as describing the regulatory framework within which EU Member States have agreed to maintain and supervise the non-state pensions sector was concerned, we were constrained at first by the long delay of the then responsible EU Commissioner Monti to follow the publication of his Green Paper of 1997 with a Communication, expected in early 1999. This Communication was signalled as the precursor to the publication of a Draft Directive, which itself would supersede the proposals in an earlier Pension Fund Directive, withdrawn by the Commission because of lack of agreement between member states. This activity, of course, illustrated that any imposition of a uniform set of rules concerning non-state, or 'second pillar' pensions, across the European Union would require a great deal of discussion between member states, would be limited in scope, and was most likely to permit a great deal of latitude in actual implementation. However, at the end of a rather extended period of discussion between ourselves and the Hungarian authorities, plus a certain amount of clarification finally emanating from Brussels, we were able to advise the Ministry of Finance and the Guarantee Fund of three general areas to which they should begin to pay some attention.

First, there is the question of the application of qualitative prudential rules (the 'prudent man' concept) to the investment behaviour of supplementary pension schemes fund management. Member States would not be allowed to maintain quantitative restrictions on the maximum and minimum levels of investment in particular investment vehicles. In Hungary, the current restriction on that 70 per cent of pension scheme assets must be in Government bonds. Even without any future pressure from potential EU membership, consideration is already being given to loosening these restrictions in Hungary. The implications of such moves for the guarantee fund system in Hungary are that it would have an adverse effect on the ability of the fund to meet larger outstanding unfunded social security, which the current purchase of government bonds helps to meet, though it would, of course, be beneficial to the development of Hungarian equity markets.

Secondly, the Communication specifies the need to remove barriers to free movement. ${ }^{9}$ A Directive already provides for seconded workers to retain the right to remain members of a pension scheme established in other member states.

Currently, the second-pillar compulsory requirement now in Hungary imposes the obligation to participate on all nonHungarian nationals of whatever age, who enter employment in Hungary for the first time. The investment return on 
the contributions of those in their 50s is likely in many cases to be insufficient to reach the normative level, leaving the PGF to meet the shortfall, particularly if the expatriates are high earners.

However, when EU obligations apply, Hungarian-seconded workers may choose to join the pension schemes in other states, if the returns are better and non-Hungarians posted to Hungary may choose to remain in their home state scheme.

Thirdly, the Hungarian government needs to be aware that overall intention of the Commission is to facilitate equal treatment of individuals seconded to work in other states and the eventual cross-participation of workers in pension scheme operating in other Member States.

Our advice covered these and subsidiary areas in our reports to our Clients. However it was important for us to point out that, as yet, these proposals were still under discussion and that member states were anxious not to accede to the imposition on centralised rules which would interfere with long established pensions systems, state, occupational or purely private for the sake of uniformity. Indeed, it is not possible to anticipate what judgments may be handed down by the European Court of Justice on the conformance of Hungary's second pillar pension provisions to the acquis communitaire on the day. However, as far as Hungary's application status is concerned, we strongly advised the Ministry of Finance, who are responsible for overall policy in this field, that they should follow closely the EU developments in this field, and to lean any likely or intended refinements of Hungarian pensions laws towards European Union requirements.

At the time of writing, Hungarian public policy is to achieve European Union accession in 2002, though more realistic expectations focus on 2005 as a more likely date. Nevertheless, as in any democratic country, especially one with a lively parliamentary process as in Hungary, there is little time to lose in beginning the administrative processes leading to convergence of Hungarian laws with the ordinances of the EU. Given the very long timescales encountered in pensions provision arrangements of all kinds, it is natural that Hungary's status as applicant to the European Union will impinge upon the development to Hungarian public policy in this field, and every future step will have to be take with this in mind.

\section{Conclusion}

This has been but a short tour d'horizon of the results of a rather elongated and sometimes confusing advisory mission. Given the current state of Hungary's administrative reform programmes and the unsettled nature of the pensions policy development in Brussels, it was inevitable that we would have to work on shifting sands. However, we endeavoured to leave our clients with a set of practical steps and methodologies which would be useful as they move forward into the next phase contingency plans, information systems proposals, forecasting tools etc. and, too, some ideas which can be further researched and developed.

In one way, the elapsed year of the project did allow, as it happened, time for the new pensions systems to get through the first full year of working successfully and the new concept of saving certainly found favour with the Hungarian people. To consolidate this initial success in the medium term, in our view, requires a lot more hard work on administrative modernisation if the new corpus of pension fund contributors are not to be disappointed. The 
emergence of Hungary into the fast-moving world of unprotected commerce has not benefited every Hungarian citizen equally by any means, and against this background it is important that those who conscientiously put by for their old age are not cheated.

As noted at the beginning, it has been impossible to lay out all the details and calculations of our advice in this contribution, even if space could conceivably permit. We know that the Hungarian administration are working on various aspects of our proposals at the time of writing, and we must bear with them as they do so. However, it is our hope that, in due course, more of the detail of work will be accessible on our web site and through the European Commission, who are anxious to promulgate more of these results when the time is ripe.

Finally, it is important to return to the matter of compulsory saving to a third party. However noble the objective of raising the rate of savings in a country for the long-term benefit of the individual and the body politic as a whole, there remains a duty of care from the state to the individual whose monies are being distrained in this way. The setting up of the Hungarian Pensions Guarantee Fund recognises this responsibility. It may be that the Guarantee Fund, set up as we originally found it, is not yet ideally configured to discharge this obligation. Nevertheless, the Supervisory and Guarantee structure as a whole clearly forms a firm basis on which a satisfactory compulsory pensions guarantee system may continue to be developed, and upon which citizens obliged to save for secondary pensions may rely in the future.

\section{References}

1 Laws LXXX \& LXXXII and Government Decrees 169-174, all of 1997.

2 The Hungarian State Pension is calculated primarily on a multiple of a proportion of the best of three of the previous five years' earnings (Ave.X $+\mathrm{X} 1+\mathrm{X} 2$ times).

3 For employees just in the state scheme the NPIA receives 6 per cent of monthly salary from each employee, with 22 per cent from the employer; under the new scheme this reduces to 1 per cent and 22 per cent respectively.

4 Act LXXXII of 1997: Art. 88(1).

5 'On the Establishment of a Unified Revenue Collection System,' Aktus (then Align) Cons. Ltd., 1996.

6 APEH.

7 Law LXXXII of 1997, Art 100.

8 Law LXXXII of 1997, Art 93 Para (2).

9 Mobility Directive 98/49. 